\title{
Deteksi Kualitas Tembakau Madura \\ Berbasis Image Processing Dan Sensor Gas
}

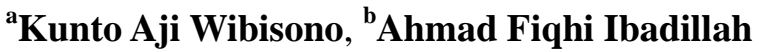 \\ ${ }^{a, b}$ Prodi Teknik Elektro Fakultas Teknik Universitas Trunojoyo Madura, Jalan Raya Telang Kamal \\ Madura 69162 \\ E-mail : kunfin35@gmail.com, fiqhi.achmad@gmail.com
}

\begin{abstract}
Abstrak:
Madura merupakan salah satu daerah penghasil tembakau di Indonseia. Tembakau Madura merupakan jenis komoditi perkebunan yang memiliki nilai ekonomi tinggi. Sebagian besar tembakau madura diserap oleh pabrik rokok sebagai bahan baku utama rokok maupun sebagai racikan atau campuran kretek. Terdapat banyak jenis varietas tembakau gunung yang ditanam petani di Madura, namun yang memiliki karakteristik khas adalah tembaku Prancak - 95. Pada penelitian ini didesain sebuah sistem gradding untuk mendeteksi kualitas tembakau Prancak - 95 madura. Deteksi kualitas daun tembakau ini didasarkan pada dua ekstraksi fitur yaitu tekstur dan aromatik. Berdasarkan kedua fitur tersebut nantinya akan diklasifikasikan dengan menggunakan tabel standard gradding tembakau ke dalam 4 kelas klasifikasi. Dari percobaan yang dilakukan dengan menggunakan input kedua fitur didapatkan nilai akurasi yang optimal. Sehingga berdasarkan data percobaan tersebut, dapat disimpulkan bahwa sistem telah dapat melakukan proses gradding kualitas tembakau Madura dengan akurat.
\end{abstract}

Kata-kata kunci : Tembakau Madura, Prancak - 95 Madura, gradding.

\section{PENDAHULUAN}

Madura merupakan salah satu penghasil jenis tembakau terbaik di Indonesia, varietas tembakau Madura yang paling diminati oleh perusahaan industri rokok adalah jenis Prancak - 95 Madura. Jenis ini memiliki karakteristik tekstur dan aroma yang khas sehingga cocok digunakan sebagai bahan baku utama maupun sebagai racikan atau campuran kretek.

Untuk lebih dapat meningkatkan nilai ekonomis dari tembakau Madura, maka perlu dilakukan penilaian terhadap kualitas daun tembaku yang melibatkan faktor internal dan eksternal. Faktor internal melibatkan human sensory (lebih pada penciuman) seperti pengujian aromatik. Sedangkan faktor eksternal 
melalui human vision (pengamatan visual), meliputi pengamatan tekstur. Penentuan nilai kualitas daun tembakau dengan menggunakan parameter sensor manusia memiliki banyak kekurangan, diantaranya adalah tidak adanya sebuah nilai referensi yang absolut, sehingga penentuan level kualitas daun tembakau hanya berdasarkan perkiraan [1].

Berbagai metode telah digunakan untuk melakukan pengujian kualitas daun tembakau diantaranya adalah dengan menggunakan metode optimasi Conjugate Gradient pada algoritma Backpropagation Neural Network. Metode ini memanfaatkan input dari kamera yang mendeteksi tekstur dan ukuran dari sampel daun tembakau, kemudian mengklasifikasikannya dalam 3 kategori[2]. Penelitian lain yang masih berkaitan dengan image processing yaitu dengan memanfaatkan Image Feature Extraction. Metode ini dilakukan dengan mengambil ekstraksi fitur gambar sampel untuk dapat melakukan klasifikasi dari daun tembaku. Fitur gambar yang digunakan sebagai classifier adalah color feature, shape feature,dan texture feature[3]. Kedua metode tersebut mampu mendefinisikan level kualitas dari sampel daun tembakau yang digunakan dalam pengujian.

Pada penelitian ini akan didesain sebuah sistem deteksi kualitas daun tembakau Madura berdasarkan ekstraksi fitur visual dan aromatik. Penelitian ini juga diharapkan dapat meningkatkan akurasi deteksi kualitas daun tembakau dibandingkan pengukuran secara manual, ataupun dapat melampaui level optimasi dari penelitian sebelumnya yang hanya menggunakan komponen data visual dari kamera sebagai komponen input.

\section{BAHASA DAN METODE}

Ekstraksi Fitur Dengan Image Processing

Fitur dari daun tembakau yang bias diekstrak dengan menggunakan teknologi image processing adalah shape feature (fitur bentuk), color feature (fitur warna), dan texture feature (fitur tekstur). Hasil dari pembacaan fitur dari daun tembakau ini kemudian diproses untuk mendapatkan klasifikasi mutu dari daun tembakau.

\section{Ekstraksi Fitur Bentuk}

Untuk mendapatkan ekstraksi fitur bentuk dari gambar objek daun tembakau dilakukan konversi citra ke biner, mengisi region yang berlubang dan melakukan operasi morphologi dengan erosi dan dilasi. Dari ekstraksi bentuk dapat dilakukan perhitungan untuk mengetahui nilai luas, panjang dan lebar objek daun tembakau[4]. Nilai luas, panjang dan lebar ini akan mewakili ekstraksi bentuk daun tembakau agar dapat diklasifikasikan. Contoh hasil ekstraksi bentuk seperti yang ditunjukkan pada 
gambar 1.

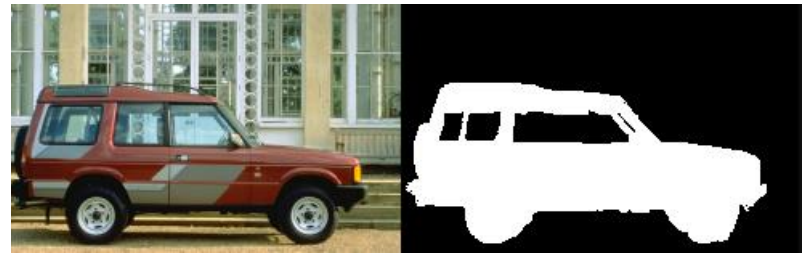

Gambar 1. Hasil ektraksi fitur bentuk pada gambar

\section{Ekstraksi Fitur Warna}

Mengesktraksi fitur warna bertujuan untuk mengetahui nilai warna RGB pada daun tembakau. Langkah awal sebelum mendapatkan nilai warna RGB pada objek daun tembakau adalah menghilangkan warna pada background dengan distance color threshold. Sehingga didapatkan hasil ekstraksi fitur yang menunjukkan warna objek daun tembakaunya saja, sedangkan untuk warna background akan hilang dan menjadi warna hitam atau warna biner 0 [5]. Contoh hasil metode ekstraksi fitur warna seperti yang ditunjukkan gambar 2 .

\section{Ekstraksi Fitur Tekstur}

Sebelum mendapatkan nilai entropy dari tekstur perlu dilakukan ekstraksi fitur tekstur pada citra objek daun tembakau. Ekstraksi fitur tekstur tersebut menggunakan metode grey level co - occurance matrix (GLM), yang didefinisikan dengan persamaan 1 berikut : $p \delta(i, j)=\{(x, y) \| f(x, y)=i, f(x+D X, y+$ $D Y)=j\}$

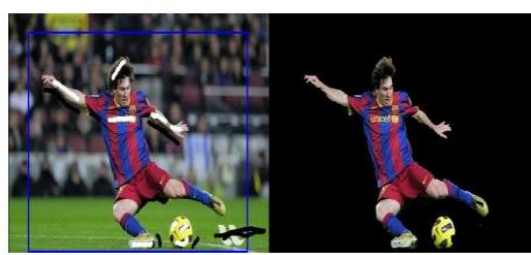

Gambar 2. Hasil ektraksi fitur warna pada gambar

\section{Sensor Gas TGS 2620}

TGS 2620 adalah tipe sensor gas semikonduktor yang memiliki sensitivitas tinggi terhadap alkohol dan jenis uap zat organik, serta menggunakan konsumsi daya yang rendah dan memiliki daya pemakaian untuk jangka waktu yang relatif lama. Untuk mendukung proses deteksinya, sensor TGS2620 membutuhkan suplai arus untuk mengaktifkan komponen heater sebesar 56mA, sedangkan sebagai packaging IC menggunakan model standar TO 5[8]. Bentuk fisik sensor gas TGS 2620 ditunjukkan pada gambar 3 berikut [6].
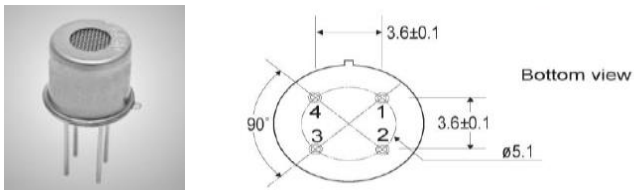

Gambar 3. Bentuk fisik dan layout footprint sensor TGS2620

Sensor TGS 2620 membutuh dua jenis input tegangan, yaitu tegangan heater $\left(\mathrm{V}_{\mathrm{H}}\right)$ dan tegangan circuit $\left(\mathrm{V}_{\mathrm{C}}\right)$. Tegangan heater $\left(\mathrm{V}_{\mathrm{H}}\right)$ digunakan sebagai suplai elemen pemanas, yang bertujuan untuk mengurangi kadar air dari sampel gas deteksi, sehingga hasil pembacaan sensor lebih akurat. Sedangkan tegangan 
circuit $\left(\mathrm{V}_{\mathrm{C}}\right)$ digunakan sebagai tegangan pengukuran yang dikombinasikan dengan besaran resistansi beban $\left(\mathrm{R}_{\mathrm{L}}\right)$ yang dipasang secara seri. Konfigurasi wiring dari sensor gas TGS2620 ditunjukkan pada gambar 4.

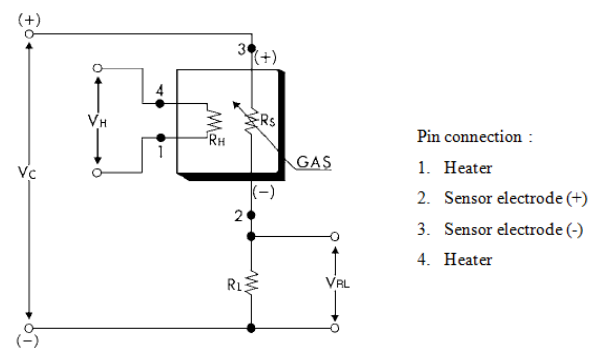

Gambar 4. Konfigurasi rangkaian sensor gas TGS2610

Untuk respon output dari sensor ditunjukkan pada persamaan 2., dengan $R_{S}$ (Resistansi Sensor) dan $\mathrm{V}_{\mathrm{RL}}$ (tegangan pada resistansi beban)

$$
R_{S}=\frac{V_{C}-V_{R L}}{V_{R L}} \times R_{L} \ldots(2)
$$

\subsection{Sistem Klasifikasi Tembakau}

$$
\text { Padilla dalam Abdallah }
$$

mendefinisikan bahwa mutu tembakau adalah gabungan dari sifat fisik, kimia, organoleptik dan ekonomi yang menyebabkan tembakau tersebut sesuai atau tidak untuk tujuan pemakaian tertentu. Mutu tembakau juga didefinisikan sebagai gabungan semua sifat kimia dan organoleptik yang dapat ditransformasi oleh perusahaan, pedagang, atau perokok yang secara ekonomis dan ditinjau dari rasa dapat diterima (Manuel Lanoscompany, 1985).

Beberapa grader (orang yang mempunyai kemampuan/ keahlian dan dipercaya oleh suatu perusahaan untuk menilai mutu/ grade tembakau) dalam melakukan penilaian mutu menggunakan penilaian berdasarkan warna, pegangan, dan aroma, kadang-kadang juga dilengkapi dengan dibakar dan dihisap asapnya untuk lebih meyakinkan (penentuan mutu dengan uji sensori). Tembakau sebagai bahan baku rokok ini memerlukan proses pemetikan daun yang benar dan tepat, baik tepat waktu, cara dan kriteria kematangan daun yang dipanen. Menurut Badri, tanaman tembakau memiliki daun sebanyak 26 sampai 32 helai. Pemilihan daun tembakau yang baik atau sempurna bisa dilakukan melalui tes aroma, kematangan berdasarkan kesempurnaan bentuk dan teksturnya [7].

Tabel 1 dan 2 menunjukkan skema klasifikasi daun tembakau berdasarkan aroma dan teksturnya yang sesuai dengan standar nasional Indonesia (SNI) untuk tembakau virginia. Pada tabel 2.1 merupakan standar klasifikasi daun tembakau berdasarkan teksturnya. Sedangkan pada tabel 2 menunjukkan klasifikasi dari rajangan daun tembakau, yang dikelompokkan dengan mendeteksi aromanya. Berdasarkan kriteria yang ditunjukkan pada tabel 1 dan 2 maka dapat dijadikan sebagai referensi untuk melakukan deteksi kualitas dari sampel daun tembakau 
Prancak - 95 Madura. Tabel ini yang selanjutnya dijadikan sebagai acuan untuk menentukan grade dari kualitas tembakau berdasarkan masukan dari sensor gas TGS2610 dan kamera.

\section{Implementasi Sistem}

Desain Ruang Pengujian

Ruang pengujian merupakan ruang terisolasi yang dilengkapi dengan perangkat pengambilan data sample seperti kamera dan sensor gas TGS2620, serta perangkat penerangan homogeny yaitu lampu. Perangkat untuk melakukan pemprosesan data terdiri atas mikrokontroler dan PC / Laptop terinstalasi di luar dari ruang pengujian. Bentuk layout ruang pengujian ditunjukkan pada gambar 6 berikut :

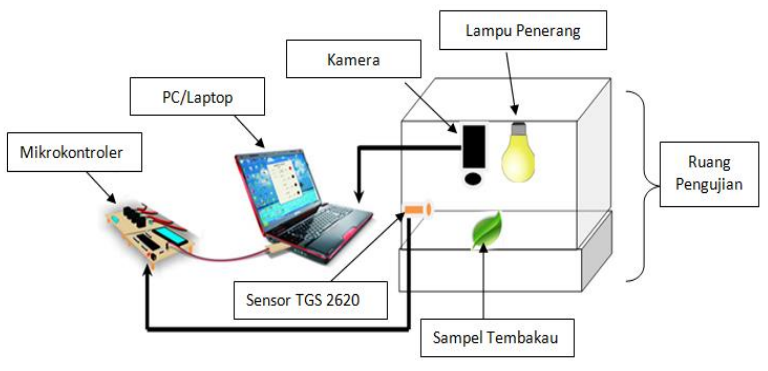

Gambar 6. Bentuk prototype ruang pengujian kualitas daun tembakau

Pada penelitian ini terdapat beberapa perangkat antara lain :

a) Sensor Gas TGS 2620 untuk mengidera aroma daun tembakau b) Mikrokontroller sebagai pengolah data dari sensor Gas dan mentransfer data ke komputer

c) USB to Serial digunakan sebagai jembatan komunikasi antara mikrokontroler dan computer

d) Sampel daun tembakau Prancak - 95 Madura dengan kategori kualitas yang berbeda

e) Kabel-kabel konektor digunakan untuk menghubungkan antara satu rangkaian elektronika dengan rangkaian yang lain

\section{HASIL DAN PEMBAHASAN}

Gambar 7 menunjukkan bentuk ruangan pengujian mutu kualitas tembakau yang didesain khusus dan dilengkapi dengan sensor TGS2610 dan kamera. Ruangan ini diset dalam konfigurasi background hitam, dengan tujuan untuk lebih memudahakan dalam melakukan prosesing gambar sampel.

Pada Gambar 8 ditunjukkan realisasi dari desain penempatan kamera sebagai device capture image. Kamera ditempatkan di bagian atas dari ruang pengujian dengan level ketinggian yang statis. Hal ini ditujukan untuk menjaga konsistensi jarak kamera dengan sampel objek. 


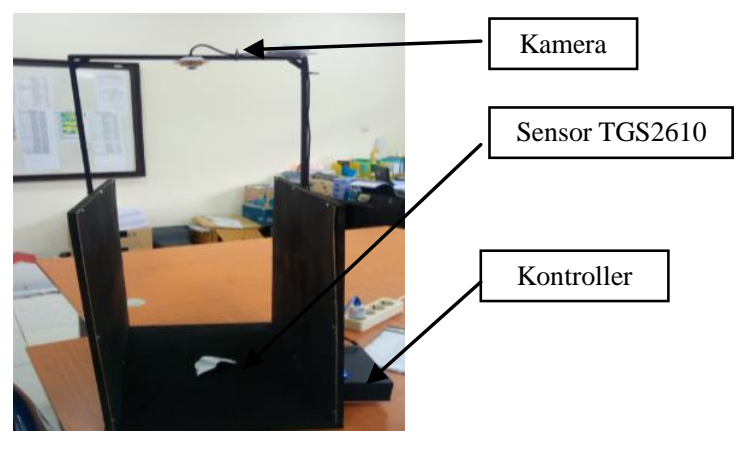

Gambar 7. Implementasi ruang pengujian daun tembakau

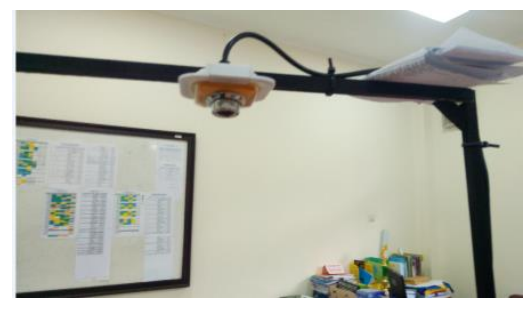

Gambar 8. Implementasi penempatan kamera

\section{Pengujian Sensor Gas TGS2610}

Pengujian sensor ini dimaksudkan untuk mengetahui karakteristik sensor, serta mencari nilai keluaran sensor yang akan dimasukkan ke ADC. Pengujian didasarkan pada respon waktu dan respon perubahan resistansi sensor terhadap kadar aromatik tembakau yang dideteksi.

Pengujian respon waktu dimaksudkan untuk mengetahui waktu yang dibutuhkan sensor gas untuk mencapai nilai yang stabil pada saat kondisi awal sensor diaktifkan. Tabel 3 berikut menampilkan respon sensor waktu pertama kali diaktifkan

Tabel 3. Respon sensor terhadap waktu

\begin{tabular}{|r|r|r|}
\hline Waktu (detik) & \multicolumn{1}{|c|}{ Nilai ADC } & \multicolumn{1}{c|}{ Tegangan } \\
\hline 1 & 963 & 4.702148438 \\
\hline 2 & 981 & 4.790039063 \\
\hline
\end{tabular}

\begin{tabular}{|r|r|r|}
\hline 3 & 898 & 4.384765625 \\
\hline 4 & 838 & 4.091796875 \\
\hline 5 & 839 & 4.096679688 \\
\hline 6 & 827 & 4.038085938 \\
\hline 7 & 816 & 3.984375 \\
\hline 8 & 807 & 3.940429688 \\
\hline 9 & 801 & 3.911132813 \\
\hline 10 & 797 & 3.891601563 \\
\hline 11 & 792 & 3.8671875 \\
\hline 12 & 789 & 3.852539063 \\
\hline 13 & 785 & 3.833007813 \\
\hline 14 & 784 & 3.828125 \\
\hline 15 & 781 & 3.813476563 \\
\hline
\end{tabular}

\section{Pengujian Ekstraksi Fitur Bentuk}

Untuk mendapatkan ekstraksi fitur bentuk dari gambar objek daun tembakau dilakukan konversi citra ke biner, mengisi region yang berlubang dan melakukan operasi morphologi dengan erosi dan dilasi. Dari ekstraksi bentuk yang sudah didapatkan seperti Gambar 9 (a) dan (b) dapat dilakukan perhitungan untuk mengetahui nilai luas, panjang dan lebar objek daun tembakau. Nilai luas, panjang dan lebar ini akan mewakili ekstraksi bentuk daun tembakau agar dapat diklasifikasikan. Untuk mendapatkan nilai luas, panjang dan lebar.

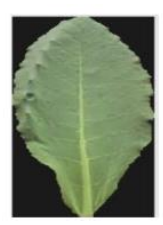

(a)

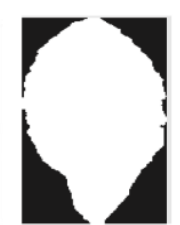

(b)
Gambar 9. (a) Gambar tembakau sebelum diekstrak

(b) Gambar output tembakau setelah ekstraksi Fitur bentuk 


\section{Pengujian Ekstraksi Fitur Tekstur}

Sebelum mendapatkan nilai entropy dari tekstur perlu dilakukan ekstraksi fitur tekstur pada citra objek daun tembakau. Ekstraksi fitur tekstur tersebut menggunakan operator. Sehingga didapatkan hasil ektraksi fitur seperti Gambar 10 (b) berikut.

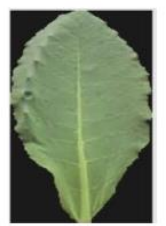

(a)

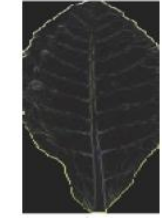

(b)

Gambar 10. (a) Gambar tembakau sebelum diekstrak

(b) Gambar output tembakau setelah ekstraksi Fitur tekstur

\section{KESIMPULAN}

Sistem deteksi kualitas tembakau yang dilengkapi dengan sensor gas TGS2610. Instrumentasi sensor TGS2610 telah didesain dengan tepat sehingga mampu mendeteksi kadar aromatic tembakau dalam level range pembacaan data antara $0-776$, sehingga dapat mengenali jenis kualitas sample tembakau. Dengan metode feature extraction pada gambar dengan menggunakan kamera maka, sebelum dilakukannya klasifikasi grade daun tembakau, pada penelitian ini melakukan tahap image acquitition, image pre-processing dan feature extraction untuk mendapatkan dataset berupa nilai angka yang selanjutnya dilakukan tahapan klasifikasi.

\section{DAFTAR PUSTAKA}

[1]. Badri, M. H. S. A.; Anthana, M.; Hardika, K.. Standart Operasional Kultur Teknis Tembakau. Surakarta; 1994.

[2]. Sari, Y., dkk. 2015, Optimasi Conjugate Gradient Pada Backpropagation Neural Network untuk Deteksi Kualitas Daun Tembakau, Konfresnsi Nasional Sistem \& Informatika, STIKOM Bali

[3].Zhang, X., dkk. 2008, Images Features Extraction of Tobacco Leaves, Congress on Image and Signal Processing, China

[4].Anilkumar.Muthevi., dkk. 2017, Leaf Classification Using Completed Local Binary Pattern Of Textures, IEEE 7th International Advance Computing Conference, India

[5].Zhang F, Zhang X. Classification and quality evaluation of tobacco leaves based on image processing and fuzzy comprehensive evaluation. Sensors (Basel, Switzerland). 2011; 11: p. 2369-84.

[6] Figaro, (2005), General Information for TGS Sensors. <URL:http://www.figarosensor.com>

[7].Dinas Perkebunan Jawa Barat, Buku Pedoman Standarisasi Mutu Tembakau: 2009

[8] Luay Fraiwan, Khaldon Lweesy, Aya Bani-Salma, Nour Mani, “A Wireless Home Safety Gas Leakage Detection System", IEEE ,pp. 11- 14, 2014. 